\title{
Boxer crabs induce asexual reproduction of their associated sea anemones by splitting and intraspecific theft
}

\author{
Yisrael Schnytzer ${ }^{\text {Corresp., }}{ }^{1}$, Yaniv Giman ${ }^{1}$, Ilan Karplus ${ }^{2}$, Yair Achituv ${ }^{1}$ \\ 1 The Mina \& Everard Goodman Faculty of Life Sciences, Bar-Ilan University, Ramat-Gan, Israel \\ 2 Institute of Animal Science, Agricultural Research Organization, The Volcani Center, Rishon Lezion, Israel \\ Corresponding Author: Yisrael Schnytzer \\ Email address: newsroolchy@gmail.com
}

Crabs of the genus Lybia have the remarkable habit of holding a sea anemone in each of their claws. This partnership appears to be obligate, at least on the part of the crab. The present study focuses on Lybia leptochelis from the Red Sea holding anemones of the genus Alicia (family Aliciidae). These anemones have not been found free living, only in association with $L$. leptochelis. In an attempt to understand how the crabs acquire them we conducted a series of behavioral experiments and molecular analyses. Laboratory observations showed that the removal of one anemone from a crab induces a "splitting" behavior, whereby the crab tears the remaining anemone into two similar parts, resulting in a complete anemone in each claw after regeneration. Furthermore, when two crabs, one holding anemones and one lacking them, are confronted, the crabs fight, almost always leading to the "theft" of a complete anemone or anemone fragment by the crab without them. Following this, crabs "split" their lone anemone into two. Individuals of Alicia sp. removed from freshly collected $L$. leptochelis were used for DNA analysis. By employing AFLP (Fluorescence Amplified Fragments Length Polymorphism) it was shown that each pair of anemones from a given crab is genetically identical. Furthermore, there is genetic identity between most pairs of anemone held by different crabs, with the others showing slight genetic differences. This is a unique case in which one animal induces asexual reproduction of another, consequently also affecting its genetic diversity. 
1 Boxer crabs induce asexual reproduction of their associated sea

2 anemones by splitting and intraspecific theft

3 Yisrael Schnytzer a, Yaniv Giman a , Ilan Karplus b and Yair Achituv a,*

4 a The Mina and Everard Goodman Faculty of Life Sciences, Bar-Ilan University, Israel

5 b Institute of Animal Science, Agricultural Research Organization, The Volcani Center,

6 Israel

7 *Corresponding author:

8 Dr. Yisrael Schnytzer

9 The Mina \& Everard Goodman Faculty of Life Sciences

10 Bar-Ilan University

11 Ramat-Gan 5290002

12 Israel

13 Tel. 972-3-5318570; Fax 972-3-7384058; Email: yair.achituv@biu.ac.il 


\section{ABSTRACT}

16 Crabs of the genus Lybia have the remarkable habit of holding a sea anemone in each of their

17 claws. This partnership appears to be obligate, at least on the part of the crab. The present study

18 focuses on Lybia leptochelis from the Red Sea holding sea anemones of the genus Alicia (family

19 Aliciidae). This species of sea anemone have not been found freely living, only in association with L. leptochelis. In an attempt to understand how the crabs acquire them, we conducted a series of behavioral experiments. Laboratory observations showed that the removal of one sea anemone from a crab induces a "splitting" behavior, whereby the crab tears the remaining sea anemone into two similar parts, resulting in a complete sea anemone in each claw after regeneration. Furthermore, when two crabs, one holding sea anemones and one lacking them, are confronted, the crabs fight, almost always leading to the "theft" of a complete sea anemone or sea anemone fragment by the crab without them. Individuals of Alicia sp. removed from freshly collected L. leptochelis were used for DNA analysis. By employing fluorescence amplified fragment length polymorphism (AFLP) it was shown that each pair of sea anemones from a given crab is genetically identical. Furthermore, there is genetic identity between most pairs of sea anemone held by different crabs, with the others showing slight genetic differences. This is a unique case in which one animal induces asexual reproduction of another and in doing so presumably limits the genetic diversity within a population of Alicia sp. held by boxer crabs. 


\section{Introduction}

Boxer crabs of the genus Lybia have the remarkable habit of carrying a sea anemone in each of its claws by means of delicate hooks, slightly embedded in the sea anemone column (Duerden 1905; Guinot 1976; Schnytzer et al. 2013). Lybia gain both nutritional and protective benefits from their sea anemones (Duerden 1905; Karplus et al. 1998; Schnytzer et al. 2013). Although crab-cnidarian associations are generally characterized by a small crab and a larger cnidarian associate who is regarded as the clear host (Thiel and Baeza 2001), in this case, the crab is the larger of the two associates, making the host-symbiont identification harder to define. Due to this "inverted" situation, the crab which is the larger of the two associates effectively controls the movement of its "host" sea anemone. Previous studies have often suggested that the crab-held sea anemones gain in addition to mobility, transport to further food sources and oxygen (Duerden, 1905; Karplus et al., 1998; Schnytzer et al. 2013). However, in a previous study, we showed that the crabs regulate the food intake of their sea anemones, and consequently control their growth, maintaining small, "bonsai" sea anemones for their use (Schnytzer et al. 2013).

The association between boxer crabs and sea anemones occurs in two genera, Lybia and Polydectus, both members of the subfamily Polydectinae Dana, 1852 (Guinot 1976; Guinot et al., 1995; Chen and Hsueh 2007). We studied Lybia leptochelis from the Red Sea. The sea anemones held by L. leptochelis have been identified as an unrecognized Alicia that has not been found freely living (D.G. Fautin and A.L. Crowther, pers. comms. 2008). The partnership between L. leptochelis and Alicia sp. appears to be obligate, at least on part of the crab, as we have never observed a crab in nature without sea anemones $(n>100)$, including juvenile crabs not long after settling from their planktonic larval stage (Schnytzer et al. 2013). In contrast to $L$. leptochelis, the sea anemone that is mostly associated with Lybia crabs is Triactis producta (Duerden 1905; Cutress 1977; Karplus et al. 1998). T. producta is widely distributed in tropical seas, and in the Red Sea it is found growing on the base of branching corals in shallow waters (Fishelson 1970; Persobs). Most Lybia inhabit the upper infralittoral zone in and around coral reefs, with access to T. producta, including L. leptochelis. However, in the Red Sea they are only found holding Alicia sp. (Schnytzer et al. 2013). When deprived of their sea anemones, the crabs make no use of their delicate claws but use their first walking legs, and sometimes the second and third ones, for the gathering of food and other behaviors usually performed by the claws (Duerden 1905; Karplus et al. 1998; Schnytzer et al. 2013). Crabs held in the laboratory without 
65

66

67

sea anemones, but provided with ad libitum food are able to survive for several months (Schnytzer et al. 2013). However, due to their "sea anemone holding" adapted claws, their inability to gather food and defend themselves in typical crab fashion, makes them unlikely to survive for long in the wild without the sea anemones.

Sea anemones are diverse and successful anthozoans, found in all marine habitats and at all depths and latitudes. Their ecological success is undoubtedly enhanced by their propensity for engaging in symbiotic relationships with other animals, such as unicellular photosynthetic algae, hermit crabs, mollusks, and clown fish (Daly et al. 2008). The life cycles of many sea anemones regularly feature, along with sexual reproduction, some form of asexual propagation (reviews by Chia 1976; Shick 1991). The occurrence and mode of asexual propagation, whether via budding, fission, pedal laceration, or apomictic parthenogenesis, varies among families, genera, and even sister-species within the same genus (Chia 1976; Francis 1988; Shick 1991), suggesting that asexual multiplication has a complex evolutionary history among sea anemones (McFadden et al. 1997). Like many facultative asexual organisms (Hughes 1989), members of a given species of sea anemone can exhibit different life histories, as different as clonal versus solitary, in response to a combination of genetic and environmental variation (e.g. Sebens 1979, 1980; Shick et al. 1979; Bucklin 1985; Lin et al. 1992; Tsuchida and Potts 1994a, b). In this study, we investigated a unique behavior of forced asexual reproduction in a sea anemone by its crab symbiont. Our laboratory observations have shown that the Lybia larvae hatch from their egg without sea anemones, ruling out vertical transfer. It has been anecdotally reported (Duerden 1905; Karplus et al. 1998) that Lybia edmondsoni tear T. producta into two fragments, which later regenerate. Karplus et al. (1998) observed that if Lybia lose both sea anemones it may resort to intraspecific theft. Sea anemone theft has been documented both in intraspecific (Giraud 2011) and interspecific (Ross 1979) hermit crab confrontations. This behavior is very size dependent, whereby the larger of the two crabs will succeed in stealing a sea anemone (Ross 1979; Giraud 2011).

In the present study, we examined three hypotheses: 1. the pair of sea anemone held by a crab is an outcome of splitting a single sea anemone; 2. crabs deprived of sea anemones will steal a whole sea anemone, or fragment, from a conspecific organism; 3. these interactions affect the genotype structure of field populations of sea anemones. 
95 96

97 98 99 100 101 102 103 104 105 106 107 108 109

To test these hypotheses, we conducted behavioral experiments intended on empirically testing the anecdotal reports of sea anemone "splitting" and intraspecific theft. In addition, we performed a genetic analysis using amplified fragment length polymorphism (AFLP; Vos et al. 1995) of sea anemone pairs held by L. leptochelis right after collection from the sea to assess the genetic relationship between each pair and to the population as a whole. AFLP is an efficient, fast and low cost DNA fingerprinting method (Bensch and Åkesson 2005; Meudt and Clarke 2007), particularly when studying organisms with limited prior knowledge of their genome (Uthicke and Conand 2005). In addition, there is an increasing interest in the use of AFLP on marine invertebrates (Uthicke and Conand 2005; Peng et al. 2012; Goncalves et al. 2014), particularly cnidarians (Amar et al. 2008; Reitzel et al. 2008; Chomsky et al. 2009; Douek et al. 2011; Brazeau et al. 2013). If the crabs in nature behave like those observed in the laboratory, namely, frequent "splitting" and theft of sea anemones, we would expect to see high levels of genetic identity between each sea anemone pair. The ultimate aim of this study is to explore splitting and intraspecific theft, which forces asexual reproduction, consequently leading to reduced genetic variability in sea anemones held by boxer crabs. 


\section{Materials and methods}

\section{Collection of animals}

113 Individuals of Lybia leptochelis and their symbiotic sea anemones Alicia sp. were collected from

114 the shallow infra littoral zone at two separated beaches in Eilat, Israel during 2007-08 and again

115 during 2013. The sites were approximately $3 \mathrm{~km}$ apart, Tur-Yam (293 $31^{\prime} 49.69 \mathrm{~N} ; 4^{\circ} 55^{\prime}$

116 36.39" E) and Red Rock Beach (29 31' 01.40" N; 34 55' 13.34" E). Only intact crabs were

117 collected. Oviparous females were not collected. Female crabs were observed carrying eggs from

$118>4 \mathrm{~mm}$ carapace width (CW; unpublished data), and therefore female crabs at least this size were 119 defined as adults. The collected crabs had a CW between 5 to $11 \mathrm{~mm}$. The sea anemones held by 120 the crabs were $\leq 2.5 \mathrm{~mm}$ pedal disc diameter (PDD). Using a small hand-held net, the crabs were 121 collected and then individually placed in $0.5 \mathrm{~L}$ bottles filled with fresh sea water from the 122 collection site, kept in a thermally insulated box and transported to Bar-Ilan University, Ramat 123 Gan, Israel. The animals were collected and maintained within the guidelines of the Israel Nature 124 and National Parks Authority (Permit no. 26103/2006/7/13).

\section{Sea anemone removal}

127 For the splitting experiment, each of the crabs had one sea anemone removed. For the theft 128 experiment both sea anemones from half of the crabs were removed. The removal process was based on the protocol presented by Karplus et al. (1998). The crab was held in a glass Petri dish with enough sea water to cover it. The crab was then placed under a binocular microscope for constant monitoring. A solution of $7.5 \% \mathrm{MgCl}_{2}$ in distilled water was used to relax the sea anemones and prevent their contraction during removal. The solution was pipetted into the Petri dish in $500-\mu \mathrm{L}$ increments every $2 \mathrm{~min}$. Removal of the sea anemones took between 50 and 80 min. On some rare occasions, it was possible to remove the sea anemone from the crab's claws without $\mathrm{MgCl}_{2}$ sedation. All the crabs, including those that did not have their sea anemones removed, were treated equally by the crab handler (i.e., sedation and contact with delicate forceps) to control for possible effects of crab "harassment".

\section{Animal measurement}


141 The crabs with and without sea anemones and the lone sea anemones were photographed in

142 small Petri dishes half filled with water placed on millimeter paper. The sea anemones were 143 photographed after settling on the bottom of the dish. The CW of each crab was measured from 144 the two furthest points on each side of the carapace (anterolateral lobes), and the PDD of each 145 sea anemone was measured using Image J (NIH freeware) software.

\section{Experimental set up - general}

148 All the crabs used for the behavioral experiments were individually maintained in the laboratory 149 in small seven liter aquaria. Each aquarium was provided with a standard corner filter and a $5 \mathrm{~cm}$ 150 long black PVC pipe lengthwise cut, which served as a shelter. The crabs and their sea anemones 151 were fed every two days ad libitum with frozen adult Artemia. For further details of the general 152 setup, day/night lighting regime, temperature and water quality in the aquaria see Schnytzer et al. 153 (2013).

\section{Crab sea anemone field data}

155 Over the course of three years we documented the size of 54 L. leptochelis, 22 male and 32 156 females, which sea anemones they held and their size. We measured the crab and sea anemone 157 sizes (as detailed above) right after collection from the sea.

\section{Sea anemone splitting experiment}

159 To empirically test the hypothesis that when left with one sea anemone, L. leptochelis will split the other, we conducted the following experiment: twenty two L. leptochelis (14 males and 8 females) had one sea anemone removed (as detailed above). We performed this for both left (10 trials) and right (12 trials) held sea anemones. Upon removal of one sea anemone, the crab was placed in a small aquarium $(18 \times 10 \times 10 \mathrm{~cm})$ and monitored with a video camera (VHS HI8, Sony or Lumix TS2, Panasonic) for a period of 2-3 hours. The trials were conducted in a closed room, behind a black curtain in order to minimize human interference. In the event that the crab split the sea anemone within this time frame the trial was terminated and the crab was returned to its normal holding aquarium. In the event that the crab did nothing, the video recording was terminated after three hours and the crab was returned to its normal holding aquarium. However, the crabs that did not split the sea anemone in the initial monitoring period were examined twice 
170 a day for a period of two weeks. In any event of splitting, the crabs and their sea anemones were

171 measured 10-14 days after the splitting and their morphology was assessed for regeneration

172 (base, column, mouth and tentacles). See above section for measurement details.

\section{Sea anemone theft experiment}

174 To assess the stealing behavior of L. leptochelis, 44 specimens of L. leptochelis were grouped 175 into 22 pairs, comprising of crabs of similar size and same gender (14 male pairs and 8 female 176 pairs; new cohort, not crabs used in previous splitting experiments). The crabs ranged in size 177 from 4-10 $\mathrm{mm} \mathrm{CW}$, with a maximal difference of $0.3 \mathrm{~mm}$ between each pair. Male-female pair 178 trials were conducted during the preliminary stages of the study. Their behavior was identical to 179 same sex pairs. However, following sea anemone theft/attempts, the fight was often followed by 180 mating. Thus, to avoid confounding behavioral factors, only same sex trials were conducted.

181 Each crab was only tested once. Each pair consisted of one crab holding both of its sea

182 anemones, and the other had both removed. The crabs without sea anemones had them removed between two to five days prior to the contest. All the crabs were handled in the same manner, even if sea anemones were not removed, to control for the harassment effect. White Styrofoam boards placed between each crab aquarium prevented the crabs from coming into visual contact with their conspecifics. A black canvas sheet was hung over the experimental setup, minimizing the visual contact between the observer and the animals. The rest of the holding conditions were as mentioned above. The contests were conducted in part under daylight conditions (14 trials), and in part under night conditions ( 8 trials). The night trials were conducted under a dim red light, as it does not appear to have an effect on their behavior (Schnytzer et al. 2013). In general, Lybia crabs are more active at night (Karplus et al. 1998; unpublished data). However, during the preliminary stages of this study we observed that the crabs were equally active when placed into the same small aquarium, so the trials were conducted under both light regimens. In the trials conducted under daylight conditions, identification of the individual crabs was conducted based on observable differences in their coloration. For the night trials, the crabs were marked with a small piece of plastic affixed to the dorsal surface of their carapace with a cyano-acrylate ester based adhesive (Super Glue).

In each trial, two crabs were introduced into an aquarium $(23 \times 23 \times 20 \mathrm{~cm})$, each inside a separate transparent glass cylinder on opposing sides of the aquarium. After 10 minutes of acclimation, the cylinders were slowly and simultaneously removed. In the event that no contact 
201 was made between the crabs after a period of 45 minutes the trial was terminated. The behavioral

202 interactions between the crabs were recorded with a digital video camera (VHS HI8, Sony or

203 Lumix TS2, Panasonic). Typically, during the preliminary trials, we observed that after coming

204 into contact, whether theft occurred or not, each crab would retreat into a corner of the aquarium

205 and no longer approached the other, thus the trials were terminated at this stage. At the end of

206 each trial, the crabs were returned to their original aquaria for a period of two weeks. During this

207 period, daily observations were made for the monitoring of sea anemone splitting activity.

\section{DNA extraction}

209 For AFLP analysis, DNA was extracted from fresh material. Genomic DNA was extracted using 210 a High Pure PCR Template Preparation Kit (Roche; Germany) according to the manufacturer's

211 protocol. Due to their small size, DNA was extracted from the entire sea anemone. DNA

212 concentration was determined by a NanoDrop ND1000 (Thermo Fisher Scientific Inc. NY) at $213260 \mathrm{~nm}$.

\section{Amplification and "fingerprinting"}

215 Eight pairs of sea anemones removed from L. leptochelis from the two above mentioned Eilat 216 beaches were analyzed (specimens 1-5 from Tur-Yam; 6-8 from Red-Rock Beach). We

217 employed AFLP genotyping (Vos et al. 1995) with modifications according to Huys and Swings 218 (1999) and Amar et al. (2008), in which radioactive labeling was replaced with fluorescent dyes.

219 Restriction enzyme digests were performed on $250 \mathrm{ng}$ of genomic DNA for $3 \mathrm{~h}$ at $37^{\circ} \mathrm{C}$ using 220 two restriction enzymes (MseI and EcoRI), followed by the ligation of respective double strand 221 adapters (EcoRI adaptor E1-CTCGTAGACTGCGTACC and E2-AATTGGTACGCAGTCTAC, 222 and MseI adaptors M1- GACGATGAGTCCTGAG and M2-TACTCAGGACTCAT). The E1 223 and M1 oligonucleotides were used as primers for pre-selective PCR amplification using $1 \mu 1$ of

224 ligation products for the second selective amplification. The PCR product was diluted 1:50, and $2255 \mu \mathrm{l}$ was used for the second amplification. We used three pairs of fluorescent labeled primers 226 (VIC, FAM, and NED, Applied Biosystems, California, U.S.A) as follows:

227 (E=GACTGCGTACCAATTC + XXX and M=GATGAGTCCTGAGTAA+XXX) : VIC-

228 E+ACC: 5' 3' with M+CTC: 5' 3'; NED- E+ACA: 5' 3' with M+CTC: 5' 3'; and FAM- E+AGC:

229 5' 3' with M+CTT: 5' 3'. The process was repeated twice (duplicates) for each sample to attain 230 maximum accuracy. 


\section{AFLP analysis}

232 DNA sequencing was performed at the Instrumentation and Service Center of the George S.

233 Wise Faculty of Life Sciences, Tel-Aviv University. The samples were analyzed using a Genetic 234 Analyzer 3100 (ABI PRISMA, Applied Biosystems). The samples were diluted and 0.3-0.5 $\mu 1$ of 235 size standard Lis 600 was added to the PCR product in the presence of formamide. Fluorescent236 labeled PCR products appear as peaks and were first analyzed using GeneScan ABI PRISM 3.7 237 software (PE Biosystems; Oda et al. 1997) to determine peak sizes in base pairs, according to the 238 size marker. Each PCR peak obtained from the samples was then aligned and converted into a 239 binary system. The results were transferred to binary scores $(0,1)$ using AFLP Macro2 software. 240 Nei's genetic distance (Nei, 1978) was calculated using POPGENE version 1.31

241 (http:/www.ualberta.ca/ fyeh). The binary results were then converted to NEXUS format and the 242 maximum parsimony option of PAUP was used to build a dendrogram of the sea anemone 243 population.

\section{Statistical analysis}

245 The sea anemone asymmetry index represents the relative difference in the pedal disc diameter 246 of the two sea anemones held by a crab, either directly from the sea or those split in the lab. The sea anemone asymmetry index (Ianem) was calculated by subtracting the pedal disc diameter of the smaller sea anemone (PDDs) from the larger one (PDDb) and dividing the difference by the larger sea anemone pedal disc diameter.

$$
\text { Ianem }=(\mathrm{PDDb}-\mathrm{PDDs}) / \mathrm{PDDb}
$$

251

252

253

254

255

256

257

258

259

Correlation analyses between field collected crabs and sea anemone sizes $(\mathrm{CW} / \mathrm{mm}$ for crabs and $\mathrm{PDD} / \mathrm{mm}$ for sea anemones) was conducted by using a Pearson's product moment correlation test. A Welch two sample t-test was used to test for differences between the size of male and female held sea anemones, to test whether or not gender has an effect on the asymmetry index. Binomial probability tests were carried out on the splitting and theft scores to determine whether the proportion of outcomes differed significantly from the expected $50 \%$ chance level. In the splitting experiment, multiple linear regression analyses were performed to assess the effect of crab gender, sea anemone size, and handedness on the time duration from the moment a sea anemone was removed until the remaining one was split. Further multiple regressions were done 
260 to test whether the asymmetry index was predicted by crab gender, time to split, sea anemones 261 size and handedness. In the theft experiment, a multiple regression was performed to test if crab

262

263

264

265

266

267

268

269

270

271

272

273

274

275

276

277

278

279

280

281

282

283

284

285

286

287

288 gender and fight outcome had an effect on fight duration. A two-way ANOVA was performed to test whether crab gender, initiator of fight (with or without sea anemones), or the interaction between them, had an effect on lag to start of fight. In case of non-normal distribution, data were $\log$ transformed. Data were checked for normality using a Kolmogorov-Smirnov test. All statistical tests used in this study employed a significance level of $\alpha=0.05$. The analyses were conducted using SPSS 15.0 or R (https://www.r-project.org/).

\section{Results}

\section{Crab-sea anemone field measurements}

During the course of this study, all L. leptochelis collected or observed in nature, well over one hundred specimens, were found holding a pair of Alicia sp. (Fig.1). The sea anemones held in the left and right claws are significantly correlated in size (Pearson's product-moment correlation, $r$ $=0.90, t_{52}=14.883, P<0.0001$; Fig. 2 ). In addition, the sea anemones significantly correlate to the size of the crab holding them (Pearson's product-moment correlation, $r=0.72, t_{52}=7.4546$; $P<0.0001$; Fig. 3). There is a highly significant difference between the size of sea anemones held by males $(\mathrm{X} \pm \mathrm{SD}=1.37 \pm 0.51 \mathrm{PDD} / \mathrm{mm})$ vs. females $(\mathrm{X} \pm \mathrm{SD}=1.92 \pm 0.57 \mathrm{PDD} / \mathrm{mm}$; Welch two sample t test; $\left.t_{42.156}=3.6513, P<0.001\right)$. In contrast, gender had no effect on the asymmetry index (male: $\mathrm{X} \pm \mathrm{SD}=9.69 \pm 9.39 \%$, female: $\mathrm{X} \pm \mathrm{SD}=12.85 \pm 10.22 \%$; Welch two sample $t$ test, $\left.t_{42.73}=1.1513, P=0.256\right)$.

\section{Sea anemone splitting experiment}

Seventeen out of the twenty two crabs holding a single sea anemone split it within six days after the removal of one of their two sea anemones. The sea anemones were split into two clones which subsequently regenerated into two intact sea anemones (Table 1). The splitting behavior was a highly significant response to sea anemone removal, performed in $77 \%$ of the trials (binomial test, $P=0.02, N=22$ ). The five crabs that did not split their sea anemones within the two week duration of the experiment were composed of both large and small individuals of both 
289

290

291

292

293

294

295

296

297

298

299

300

301

302

303

304

305

306

307

308

309

310

311

312

313

314

315

316

317

318

319

genders and their single sea anemone pedal disc diameter overlapped with that of sea anemones which were split by the crabs (Table 1).

Time from the removal of one sea anemone until the splitting of the remaining one was highly variable, ranging from one hour to six days with a mean $( \pm \mathrm{SD})$ of $29.2 \pm 35.2$ hours until sea anemone splitting. Time to split was not well predicted by crab gender (males: $\mathrm{X} \pm \mathrm{SD}=25.5 \pm$ $41.32 \mathrm{~min}$; females: $\mathrm{X} \pm \mathrm{SD}=36.0 \pm 21.5 \mathrm{~min}$ ), sea anemone size or handedness (multiple linear regression; Table $2 \mathrm{~A})$.

The actual splitting process was observed several times in its entirety and lasted between 1 min and over 2 hours. Typically, the actual process of splitting lasted approximately 20 minutes, taking the following course: the crab held the sea anemone across the column, with the pedal disc facing upward and the oral disc and tentacles facing downward. The crab then took hold of the sea anemone with its free claw, thus holding the sea anemone in the aforementioned downward conformation between both claws (Fig. 4A-B; Video 1). Next, the crab slowly began stretching the sea anemone between both claws in an outward motion, utilizing its front walking legs in order to surgically tear the sea anemone in half (Fig. 4C). Occasionally, the crab momentarily ceased the stretching to re-grasp the sea anemone in what appears to be the most centered conformation possible, so that the final splitting will produce two equal parts. Once the sea anemone has been re-grasped, the crab initiated the stretching once again, slowly pulling the sea anemone from the center outwards. Once the majority of the sea anemone was split into two, there were often final strands of sea anemone tissue connecting each newly split sea anemone, which were torn by the front walking legs (Fig. 4D-E). Once the splitting process was complete the crab had two identical clones held in each claw (Fig. 4F).

Overall, following splitting and sea anemone regeneration, the pedal disc surface area of the two new sea anemones increased substantially $(\mathrm{X} \pm \mathrm{SD}=10.0 \pm 23.2 \%)$ in comparison to the single sea anemone prior to splitting. However, in some cases, the combined pedal disc surface area of the two new sea anemones was similar or even smaller than that of the original sea anemone. This phenomenon is reflected in the large standard deviation of the increase in pedal disc surface area following splitting.

The sea anemone asymmetry index calculated for the two sea anemones resulting from the splitting process was overall small $(\mathrm{X} \pm \mathrm{SD}=8.5 \pm 8.7 \%)$. The asymmetry index ranged however from 0 to $26 \%$ reflecting the high value of the standard deviation of the calculated 
320 index. The multiple linear regression model (Table 2B) shows that both crab gender and time to

321 split from sea anemone removal were significantly related to the asymmetry index, sea anemone

322 size was weakly related, and handedness was unrelated.

323

\section{Sea anemone theft experiment}

325

326

327

328

329

330

331

332

333

334

335

336

337

338

339

340

341

342

343

344

345

346

347

348

349

350

In $73 \%$ of the staged encounters between crabs with and without sea anemones, intense fighting took place, culminating in sea anemone theft (binomial test, $P=0.05, N=22$; Table 3 ). In $44 \%$ of the contests, an entire sea anemone was stolen, in $37 \%$ a sea anemone fragment was taken, and in the remaining $18 \%$ the crab without sea anemones came away with two sea anemone fragments (Table 3). Out of the six remaining trials which did not end in sea anemone theft, in five cases the crabs refrained from fighting, in two of them they did not move over a period of 45 minutes (no contact) and in the three remaining cases the crabs only made gentle leg contact before separating. The only trial in which there was aggressive contact, but no theft occurred was the shortest recorded contest (1:23 min) where the crabs mainly collided into each other but lacked the typical contest structure described below.

Crabs of both genders with and without sea anemones were equally likely to initiate a fight (binomial test, $P=0.6291, N=17$ ). Contests between crabs started on average $15.5 \pm 6.5$ minutes after the acclimation period. A two-way ANOVA revealed that neither crab gender (males: $\mathrm{X} \pm \mathrm{SD}=16.2 \pm 7.5$; females: $\mathrm{X} \pm \mathrm{SD}=14.3 \pm 4.3$ ), nor whether the initiator was deprived or in possession of sea anemones had a significant effect on time until the start of fighting (Table 4).

Typically, after being placed together and the cylinders removed, one contestant would approach the other. For the sake of illustration, we will describe a crab with sea anemones approaching one without them. As the crab with sea anemones came within a close proximity of the crab without sea anemone, the crab with sea anemones held its sea anemones at a distance away from the other crab (Fig. 5A). Next, the initiator gently touched the other crab with the tip of its first walking leg for about a minute (Fig. 5B). Following this gentle leg contact, the two crabs typically proceeded to move into a back to back configuration (Fig. 5C). Following this, the crabs rapidly locked their walking legs and commenced a close physical struggle grasping one another with their legs forming a tight ball. It is important to note that during these phases both crabs distanced their claws (holding sea anemones or vacant) as far as possible from the 
351 other (Fig. 5D). Next, the crab without sea anemones strived to move into a dominant position,

352 typically on top of the crab holding sea anemones (Fig. 5E). The crab without sea anemones then

353 proceeded to try and hold one of the opposing crab's claws and lock it with the aid of its walking

354 legs. No use was made of its unoccupied delicate claws (Fig. 5F). Upon achieving a claw lock of

355 the opposing crab (Fig. 5G), the crab without sea anemones proceeded to remove the sea

356 anemone held by the other crab. At first, it made use of its first walking leg to pry at the claw

357 holding the sea anemone. After it has been pried open sufficiently, the attacking crab for the first

358 time used its vacant claw to take hold of the sea anemone (Fig. 5H). Sometimes, an entire sea

359 anemone was taken and sometimes only a fragment was torn off. We never witnessed a contest

360 where two whole sea anemones were stolen. Typically, after a whole or partial sea anemone has

361 been taken the contestants broke off and "returned to their corners" (Video 2).

362 The fight duration was extremely variable, ranging from between less than a minute to 40

363 minutes with average $( \pm \mathrm{SD})$ durations of $17.5 \pm 12.4$ minutes per fight. A multiple linear

364 regression model failed to show a connection between fight duration and crab gender (males: X

$365 \pm \mathrm{SD}=17.7 \pm 11.5$; females: $\mathrm{X} \pm \mathrm{SD}=17.2 \pm 15.0$ ) or contest outcome (i.e., removal of a

366 complete sea anemone or a sea anemone fragment) (Table 5). Sea anemone splitting was

367 observed in all instances where a complete or a fragment of the sea anemone was stolen (Table

368 3). In the event that two fragments were stolen, splitting was not observed.

369 AFLP

370 Sixteen sea anemones from eight crabs were analyzed. The three sets of fluorescent labeled 371 primers (VIC, NED, and FAM) revealed 43, 30 and 71 bands, respectively (total = 144 bands).

372 The sizes of the amplified fragments ranged between 60 to $430 \mathrm{bps}$. The majority of the bands

373 were monomorphic, and only $24.9 \%(\mathrm{FAM}=15.5 \%$; $\mathrm{NED}=26.6 \%$; VIC $=32.5 \%)$ were

374 polymorphic. The fingerprint profiles of all sea anemone pairs taken from a single crab were

375 identical. Between the pairs, six out of the eight sea anemones pairs (four from Tur-Yam and two

376 from Red-Rock) were identical, and the two other pairs (one from Tur-Yam and the other from

377 Red-Rock) exhibited independent banding patterns from the other six. A maximum parsimony

378 dendogram (Fig. 6), as well as Nei's (1978) mean genetic distance analyses (Table 6), revealed

379 the presence of three genotypes. 


\section{Discussion}

382 Symbiotic sea anemones

383 L. leptochelis from the Gulf of Eilat represent a unique case among Lybia crabs with regard to

384

385

386

387

388

389

390

391

392

393

394

395

396

397

398

399

400

401

402

403

404

405

406

407

their symbiotic sea anemones. Most Lybia crabs are found holding the sea anemone Triactis producta, while L. leptochelis from the Gulf of Eilat hold a pair of Alicia sp. (Schnytzer et al. 2013). Free living specimens of this unidentified species of Alicia were not found in or around the crab's habitat over the course of some four years of research in the area, and there is no previous description of them in the literature.

All crabs found in nature during this study were holding a pair of Alicia sp. Even the smallest crabs found ( $2 \mathrm{~mm} \mathrm{CW}$ ), probably not long after the megalopa settled, already possessed a pair of minute sea anemones. In a previous study we showed that L. leptochelis steal food from their held sea anemones, thus regulating their growth and subsequent size (Schnytzer et al. 2013). Indeed, there is a significant correlation between crab and sea anemone sizes (Fig. 3), suggesting an optimal carrying size. Females hold significantly larger sea anemones than males of similar size. Currently, we can only speculate on the nature of this 'sexual dimorphism'. Perhaps it aids in heightened protection provided by larger sea anemones, an evident advantage to egg carrying females. Lybia crabs are presumably obligatory symbionts of their held sea anemones as most previous studies also report that all wild caught crabs were found holding a pair of sea anemones (Duerden 1905; Karplus et al. 1998; Yanagi and Iwao 2012; Schnytzer et al. 2013). Only one study reported collecting several L. tessellata without sea anemones (Borradaile 1902). Interestingly, the sea anemone most commonly associated with Lybia crabs (Karplus et al. 1998; Yanagi and Iwao 2012), T. producta, is found freely living in Eilat (Fishelson 1970; persobs), yet they have never been observed in association with L. leptochelis. Similar to our case, Duerden (1905) reported that the sea anemones, Sagartia and Bunodeopsis, held by Melia tessellate (=Lybia edmondsoni; see Ross 1974) were not found freely living around the crabs habitat, during a careful search made over the course of three months. The apparent "rarity" of Alicia sp. in conjuncture with all the observed crabs holding sea anemones gives rise to the 
408 question of how they obtain them. Of course we cannot rule out the possibility that the sea

409 anemones do occur in or around the crab's habitat and have yet to be found.

410

\section{Sea anemone splitting}

412 Duerden (1905) and later Karplus et al. (1998) provided anecdotal evidence of Lybia crabs

413 splitting sea anemones. We have empirically shown for the first time that in the vast majority of

414 cases, a crab which has one sea anemone removed will split the other into two new ones. As our

415 data show, this behavior appears to be independent of any crab or sea anemone physical

416 characteristics, suggesting this is a dominant and widespread behavior. By splitting a sea

417 anemone, the crab effectively induces asexual reproduction of the sea anemone. Indeed, all split

418 sea anemones were observed fully regenerated within a matter of days. Consequently, sea

419 anemone splitting appears to be a well-orchestrated behavior, conducted with apparent care for

420 the final outcome, i.e. two new viable sea anemones (Fig. 4 and Video 1). Fission, i.e.

421 programmed physical separation, is a well-known form of sea anemone asexual reproduction

422 (Geller et al. 2005; Sherman and Ayre 2008). However, as the classic definition implies, this is

423 usually a self-regulated form of asexual reproduction. To our knowledge, there are no other

424 known examples of other marine organism which physically induce this behavior in sea

425 anemones. Commonly, animals associated with sea anemones will either reside around or within

426 them, such as clownfish (Karplus 2014) or a wide range of crustaceans (Jonsson et al. 2001;

427 Duris et al. 2013; Fernandez-Leborans 2013). Alternatively, animals which carry sea anemones

428 on them, such as hermit crabs (Williams and McDermott 2004) will either locate them freely

429 living or engage in interpecific and intraspecific theft (Ross 1979; Giraud 2011; see below for

430 further details). Crustaceans commonly place their associated sea anemone one their shell,

431 carapace or walking legs (Guinot et al. 1995). The habit of physically holding sea anemones in

432 their claws appears to be unique to the order Polydecdinae (Duerden 1905; Guinot 1976), a

433 factor which may explain why this splitting behavior arose and is unknown among other crabs.

434 Interestingly, our analysis revealed that time to split had a significant, albeit small, positive effect

435 on the asymmetry index, indicating that a shorter time to split results in more equally sized sea

436 anemones. Although this experiment was confined to laboratory conditions, we may cautiously

437 assume that splitting sea anemones is presumably part of the crab-sea anemone acquisition 
438 mechanism in nature (see AFLP results below). As mentioned above, our field data also supports

439 this claim in that there is a highly significant correlation between sea anemone pair size held by 440 crabs caught in the wild (Fig. 2).

441

\section{Sea anemone theft}

443 There is only one report in the literature of sea anemone theft in Lybia crabs. Karplus et al. 444 (1998) reported on one observation of sea anemone theft. This isolated case was observed when 445 two small L. edmondsoni with sea anemones were introduced into an aquarium with a large 446 conspecific deprived of sea anemones. Our experiment shows for the first time that this is a 447 highly common behavior, occurring in the vast majority of instances, irrespective of sex, in 448 which two crabs are placed together, one holding sea anemones and the other without. 449 Interestingly, the initiation of contact was irrespective of sea anemone possession. One might 450 have thought that this would be less likely due to the apparent "high value" of their sea 451 anemones. These encounters exhibited a similar sequence of behaviors in all the trials we 452 conducted. Upon initial contact, the initiator always "feels" the opponent's leg. In the three trials 453 where contact was made but no fight was initiated, the crabs separated after this leg contact 454 phase. Pre-fight assessment is a well-known behavior, often dictating whether or not animals will 455 commence fighting (Arnott and Elwood 2009). As can be seen quite clearly in the example video 456 (Video 2), these battles are at times quite violent in their appearance. However, in no instances 457 did we observe a crab being injured or killed. Unlike splitting, intraspecific sea anemone theft 458 has been observed in hermit crabs, yet intraspecific theft is far less common. In hermit crabs, it is 459 always the hermit crab lacking sea anemones which initiates the fight, and the larger of the two 460 who prevails (Ross 1979, 1983; Giraud 2011). In many cases amongst crustaceans, there is a 461 clear size advantage regarding resource acquisition (Jaroensutasinee and Tantichodok 2002; Pratt 462 et al. 2003; Arnott and Elwood 2009). In contrast, this appears not to be the case with boxer 463 crabs. Lybia crabs presumably acquire their sea anemones sometime after settling from the larval 464 stage. Although quite difficult to find, we did manage to collect three tiny specimens (2-3 mm $465 \mathrm{CW}$ ), and after removing their sea anemones we conducted three preliminary contests between 466 them and fully grown crabs $(8-10 \mathrm{~mm} \mathrm{CW})$. In all cases it was the small crab which initiated the

467 fight, and in all instances it managed to come away with a sea anemone fragment or a full sea 
468 anemone (Video 3). As is evident in the video the small crab is quite determined to get a sea

469 anemone, and despite the great difference in size it manages in much the same way as larger

470 crabs to succeed. Although these are preliminary observations and under laboratory conditions,

471 they are insightful into the possible mechanism of sea anemone acquisition in nature by small

472 individuals. Following our observations in the splitting experiment, the crabs that stole a

473 complete sea anemone or a fragment proceeded to split it up to two weeks after the contest.

474 Interestingly, the crabs that stole two fragments, holding one in each claw, would not split.

475 Presumably the instinct to split is not induced when both claws are occupied.

476 AFLP

477 Genetic markers have been successfully used to determine the asexual origin of broods of sea 478 anemone (Schaefer 1981; Carter and Thorp 1979; Gashout and Ormond 1979; Monteiro et al.

479 1998). The rationale behind the use of molecular markers to study asexual reproduction is that it 480 is extremely unlikely that two sexually produced individuals will be identical over a large 481 number of polymorphic loci. Putative clone mates are, thus, those individuals in the population 482 analyzed that have identical multiloci genotypes when the cumulative probability of that identity 483 is very small (Monteiro et al. 1998). Using amplified fragment-length polymorphism (AFLP) 484 markers (Vos et al. 1995), a well-established method for cnidarian genotyping (Amar et al. 2008; 485 Douek et al. 2011; Brazeau et al. 2013),we demonstrate that the Alicia sp. population held by $L$. 486 leptochelis has a particularly small number of genotypes. Remarkably, each pair of sea anemones 487 held by a single crab is identical, strongly suggesting that they are clones obtained by splitting a 488 single sea anemone into two new ones. This is congruent with our behavioral observations of 489 theft and splitting among the crabs, indicating that crab induced splitting is a major reproductive 490 strategy of the sea anemone. Furthermore, the significant size correlation between sea anemone pairs from wild caught crabs adds credence to this assertion. It is still unclear how, where and when the crab obtains its sea anemones in nature. It is reasonable to assume that although splitting and theft occurs in nature, it does not exhibit the full picture of the acquisition mechanism. The AFLP profiles of 6 out of 8 sea anemone pairs were identical, containing representative pairs from both locations sampled. Of the remaining two genotypes, one originates from Tur-Yam and the other from Red-Rock. These beaches are approximately $3 \mathrm{~km}$ apart, separated by a large man made barrier in between them, the Eilat port complex, spanning approximately 850 meters. 
499 The remaining two genotypes are from each location (Fig. 6 and Table 6). Due to strict collection

500 regulations and a general scarcity of the animals, we limited the genetic part of the study to a 501 small sample size. Thus the scarcity of the less frequent genotypes at each of the two sample

502 localities may be due to a sampling bias, not fully reflecting the sea anemones population level

503 genetic profile. Brazeau et al. (2013) found that even when using a small sample size, in a

504 limited geographic area, AFLP is a powerful tool for investigating genetic differences among

505 individuals and warrants strong reconsideration as a tool in population genomic analysis,

506 particularly when sampling is constrained. Another crab induced behavior which presumably

507 contributes to the maintenance of a crab specific sea anemone genotype is molting. Over 20

508 times (unpublished data) throughout the course of this study we observed molting. Typically, a

509 newly molted crab was found in its aquaria with sea anemones in its claws while the exuviae was

510 deprived of them. Upon the completion of molting, the crab would retake its sea anemones from

511 the claws of the exuviae, each to its original claw (Video 4).

\section{Conclusions}

513 We have shown that the Lybia-sea anemone acquisition mechanism is composed of a unique 514 behavioral repertoire. Both sea anemone theft and splitting are highly significant behaviors in 515 laboratory held L. leptochelis. The genetic analysis of sea anemone pairs from wild caught crabs

516 show genetic identity within the pairs and also between pairs, this provides further support to the 517 hypothesis that the genetic profile of the sea anemone population are modulated to some extent

518 by the crab behavior. This association is a rare and perhaps unique example of one animal which 519 not only regulates the feeding and growth of its associate (Schnytzer et al. 2013), but also 520 controls its asexual reproduction. The exploration of the genetic profiles of the so far not found

521 freely living Alicia sp. as well as expanding the study to further Lybia populations would greatly

522 enhance our understanding of the role played by the crabs through splitting and theft in affecting 523 the genetic diversity of their cnidarian associates.

\section{Acknowledgments}

525 We thank the staff at the Interuniversity Institute for Marine Sciences in Eilat for their hospitality

526 and assistance with the field work. We thank D.G. Fautin, A.L. Crowther and D. Guinot for

527 identifying the animals. We are grateful to Adi Schnytzer, Jennifer Benichou Cohen Israel and 
528 Dr. Yury Kaminer for helping with the statistical analysis, and E. Costi for helping to set up the

529 lighting system and for technical support with the aquarium room. A special thanks to RivQua

530 Bar-Noy for drawing the illustrations. This research is part of the MSc thesis requirements for

531 Yisrael Schnytzer and Yaniv Giman under the supervision of Yair Achituv and Ilan Karplus at

532 The Mina and Everard Goodman Faculty of Life Sciences, Bar Ilan University, Israel.

533

\section{References}

535 Amar KO, Douek J, Rabinowitz C, Rinkevich B (2008) Employing of the amplified fragment

536 length polymorphism (AFLP) methodology as an efficient population genetic tool for symbiotic

537 cnidarians. Mar Biotechnol 10:350-357

538 Arnott G, Elwood RW (2009) Assessment of fighting ability in animal contests. Anim Behav

539 77:991-1004

540 Bensch S, Åkesson M (2005) Ten years of AFLP in ecology and evolution: why so few animals?

541 Mol Ecol 14:2899-2914

542 Borradaile LA (1902) Marine crustaceans III The Xanthidae and some other crab in: Gardiner JS

543 (Ed) The Fauna and Geography of the Maldives and Laccadive Archipelagos Vol 1 Part 3

544 University Press Cambridge pp.237-271

545 Brazeau DA, Lesser MP, Slattery M (2013) Genetic structure in the coral Montastraea

546 cavernosa: Assessing genetic differentiation among and within mesophotic reefs. PLoS ONE 8:

$547 \mathrm{e} 65845$

548 Bucklin A (1985) Biochemical genetic variation growth and regeneration of the sea anemone

549 Metridium of British shores. J Mar Biol Assoc UK 65:141-157

550 Carter MA, Thorp CH (1979) Reproduction of Actinia equina L var mesembryanthemum. J Mar

551 Biol Assoc UK 59:989-1001

552 Chen SY, Hsueh PW (2007) Polydectus cupulifer (Latreille 1812) (decapoda xanthidae): First

553 record from Taiwan. Crustaceana 80:411-415

554 Chia FS (1976) Sea anemone reproduction: Patterns and adaptive radiations in: Mackie GO (Ed)

555 Coelenterate Ecology and Behavior. Plenum Press New York pp:261-270

556 Chomsky O, Douek J, Chadwick NE, Dubinsky Z, Rinkevich B (2009) Biological and

557 population-genetic aspects of the sea anemone Actinia equina (Cnidaria: Anthozoa) along the

558 Mediterranean coast of Israel. J Exp Mar Biol Ecol 375:16-20 
559 Cutress CE (1977) Corallimorpharia Actiniaria Ceriantharia in: Devaney DM Eldredge LG (Eds)

560 Reef and Shore Fauna of Hawaii. Bishop Museum Press Honolulu pp:130-147

561 Daly M, Chaudhuri A, Gusmão L, Rodriguez E (2008) Phylogenetic relationships among sea

562 anemones (Cnidaria : Anthozoa : Actiniaria). Mol Phylogenet Evol 48:292-301

563 Douek J, Amar KO, Rinkevich B (2011) Maternal-larval population genetic traits in Stylophora 564 pistillata a hermaphroditic brooding coral species. Genetica 139:1531-1542

565 Duerden JE (1905) On the habits and reactions of crabs bearing actinians in their claws. Proc

566 Zool Soc Lond 2:494-511

567 Duris Z, Ates AS, Ozalp HB, Katagan T (2013) New records of Decapod Crustaceans

568 (Decapoda: Pontoniinae and Inachidae) associated with sea anemones in Turkish waters. Med

569 Mar Sci 14:49-55

570 Fernandez-Leborans G (2013) A review of cnidarian epibionts on marine crustacea. Oceanol

571 Hydrobiol Stud 42:347-357

572 Fishelson L (1970) Littoral fauna of Red Sea - Population of non-scleractinian anthozoans of

573 shallow waters of Red Sea (Eilat). Mar Biol 6:106-116

574 Francis L (1988) Cloning and aggression among sea anemones (Coelenterata Actiniaria) of the

575 rocky shore. Biol Bull 174:241-253

576 Gashout SE, Ormond RFG (1979) Evidence for parthenogenetic reproduction in the sea anemone

577 Actinia equina L. J Mar Biol Assoc UK 59:975-987

578 Geller JB, Fitzgerald LJ, King CE (2005) Fission in sea anemones: Integrative studies of life

579 cycle evolution. Integr Comp Biol 45:615-622

580 Giraud C (2011) Intraspecific competition stealing and placement of the symbiotic sea anemone

581 Calliactis tricolor by the hermit crab Dardanus pedunculatus. Student Research Papers Fall

5822011 UCB Moorea Class: Biology and Geomorphology of Tropical Islands Berkeley Natural

583 History Museum University of California at Berkeley Berkeley CA

584 Gonçalves MM, de Almeida Regitano LC, Dami C, Salgado CC, de Freitas PD, Teixeira AKG,

585 Galetti-Junior PM (2014) Inheritance of AFLP markers and genetic linkage analysis in two full-

586 sib families of the marine shrimp Litopenaeus vannamei (Crustacea Decapoda). Advances in

587 Bioscience and Biotechnology 2014

588 Guinot D (1976) Constitution de quelques groupes naturels chez les crustaces decapodes

589 brachyoures 1 La superfamille des Bellioidea et trois sous-familles de Xanthidae( Polydectinae 
590 Dana Trichiinae de haan Actaeinae Alcock). Mem Memoir Mus Natl Hist Series A Zoologie

$59197: 1-308$

592 Guinot D, Doumenc D, Chintiroglou CC (1995) A review of the carrying behavior in brachyuran

593 crabs with additional information on the symbioses with sea anemones. Raffles Bull Zool

594 43:377-416

595 Hughes RN (1989) Functional Biology of Clonal Animals. Chapman and Hall New York

596 Huys G, Swings J (1999) Evaluation of a fluorescent amplified fragment length polymorphism

597 (FAFLP) methodology for the genotypic discrimination of Aeromonas taxa. FEMS Microbiol

598 Lett 177:83-92

599 Jaroensutasinee M, Tantichodok P (2002) Effects of size and residency on fighting outcomes in

600 the fiddler crab Uca vocans hesperiae (decapoda brachyura ocypodidae). Crustaceana 75:1107-

$601 \quad 1117$

602 Jonsson LG, Lundalv T, Johannesson K (2001) Symbiotic associations between anthozoans and

603 crustaceans in a temperate coastal area. Mar Ecol Prog Ser 209:189-195

604 Karplus I (2014) Symbiosis in Fishes: The Biology of Interspecific Partnerships. Wiley-

$605 \quad$ Blackwell

606 Karplus I, Fiedler GC, Ramcharan P (1998) The intraspecific fighting behavior of the Hawaiian

607 boxer crab Lybia edmondsoni - Fighting with dangerous weapons? Symbiosis 24:287-301

608 Lin J, Chen CP, Chen IM (1992) Sexual and asexual reproduction of Anthopleura dixoniana

609 (Anthozoa Actiniaria) - periodicity and regulation. Mar Biol 112:91-98

610 McFadden CS, Grosberg RK, Cameron BB, Karlton DP, Secord D (1997) Genetic relationships

611 within and between clonal and solitary forms of the sea anemone Anthopleura elegantissima

612 revisited: Evidence for the existence of two species. Mar Biol 128:127-139

613 Meudt HM, Clarke AC (2007) Almost forgotten or latest practice? AFLP applications analyses

614 and advances. Trends Plant Sci 12:106-117

615 Monteiro FA, Russo CAM, Solé-Cava AM (1998) Genetic evidence for the asexual origin of

616 small individuals found in the coelenteron of the sea anemone Actinia bermudensis McMurrich.

617 Bull Mar Sci 63:257-264

618 Nei M (1978) Estimation of average heterozygosity and genetic distance from a small number of

619 individuals. Genetics 89:583-590 
620 Oda S, Oki E, Maehara Y, Sugimachi K (1997) Precise assessment of microsatellite instability

621 using high resolution fluorescent microsatellite analysis. Nucleic Acids Res 25:3415-3420

622 Pratt AE, McLain DK, Lathrop GR (2003) The assessment game in sand fiddler crab contests for

623 breeding burrows. Anim Behav 65:945-955

624 Peng M, Chen XL, Jiang WM, Yang CL, LI YM (2012) The population genetic diversity of

625 different geographical Pteria penguin revealed by faflp analysis. Acta Hydrobiologica Sinica

$62636: 102-108$

627 Reitzel AM, Darling JA, Sullivan JC, Finnerty JR (2008) Global population genetic structure of

628 the starlet sea anemone Nematostella vectensis: multiple introductions and implications for

629 conservation policy. Biol Invasions 10:1197-1213

630 Ross DM (1974) Behavior patterns in associations and interactions with other animals in:

631 Muscatine L Lenhoff HM (Eds) Coelenterate Biology Academic Press London San Francisco

632 and New York pp:281-312

633 Ross DM (1979) Stealing of the symbiotic sea anemone Calliactis parasitica in intraspecific and

634 interspecific encounters of 3 species of Mediterranean pagurids. Can J Zool 57:1181-1189

635 Ross DM (1983) Symbiotic relations in: Vernberg FJ Vernberg WB (Eds) The Biology of

636 Crustacea Vol 7 Behavior and Ecology Academic Press New York pp:163-212

637 Schaefer W (1981) Reproduction and sexuality of Cereus pedunculatus and Actinia equina

638 (Anthozoa Actiniaria). Helgol Meer 34:451-461

639 Schnytzer Y, Giman Y, Karplus I, Achituv Y (2013) Bonsai sea anemones: Growth suppression

640 of sea anemones by their associated kleptoparasitic boxer crab. J Exp Mar Biol Ecol 448:265-

$641 \quad 270$

642 Sebens KP (1979) Energetics of asexual reproduction and colony formation in benthic marine

643 invertebrates. Am Zool 19:683-697

644 Sebens KP (1980) The regulation of asexual reproduction and indeterminate body size in the sea

645 anemone Anthopleura elegantissima (Brandt). Biol Bull 158:370-382

646 Sherman CDH, Ayre DJ (2008) Fine-scale adaptation in a clonal sea anemone Evolution

$64762: 1373-1380$

648 Shick JM (1991) A Functional Biology of Sea anemones. Chapman and Hall New York

649 Shick JM, Hoffmann RJ, Lamb AN (1979) Asexual reproduction population structure and

650 genotype-environment interactions in sea anemones. Am Zool 19:699-713 
651 Thiel M, Baeza JA (2001) Factors affecting the social behaviour of crustaceans living

652 symbiotically with other marine invertebrates: A modelling approach. Symbiosis 30:163-190

653 Tsuchida CB, Potts DC (1994a) The effects of illumination food and symbionts on growth of the

654 sea anemone Anthopleura elegantissima (Brandt 1835) II. Clonal growth. J Exp Mar Biol Ecol

$655 \quad 183: 243-258$

656 Tsuchida CB, Potts DC (1994b) The effects of illumination food and symbionts on growth of the 657 sea anemone Anthopleura elegantissima (Brandt 1835) I. ramet growth. Journal of Experimental 658 Marine Biology and Ecology 183:227-242

659 Uthicke S, Conand C (2005) Amplified fragment length polymorphism (AFLP) analysis 660 indicates the importance of both asexual and sexual reproduction in the fissiparous holothurian 661 Stichopus chloronotus (Aspidochirotida) in the Indian and Pacific Ocean. Coral Reefs 24:103$662 \quad 111$

663 Vos P, Hogers R, Bleeker M, Reijans M, Vandelee T, Hornes M, Frijters A, Pot J, Peleman J, 664 Kuiper M, Zabeau M (1995) AFLP: A new technique for DNA fingerprinting. Nucleic Acids Res 665 23: 4407-4414

666 Williams JD, McDermott JJ (2004) Hermit crab biocoenoses: a worldwide review of the 667 diversity and natural history of hermit crab associates. J Exp Mar Biol Ecol 305:1-128 668 Yanagi K, Iwao K (2012) Mystery of the sea anemone held by the boxer crab Lybia tessellata (in 669 Japanese). Midoriishi - Report of the Akajima Marine Science Laboratory 23:31-36 670

671 


\section{Figure 1}

Lybia leptochelis collected directly from the sea holding typically similar sized Alicia sp. anemones.

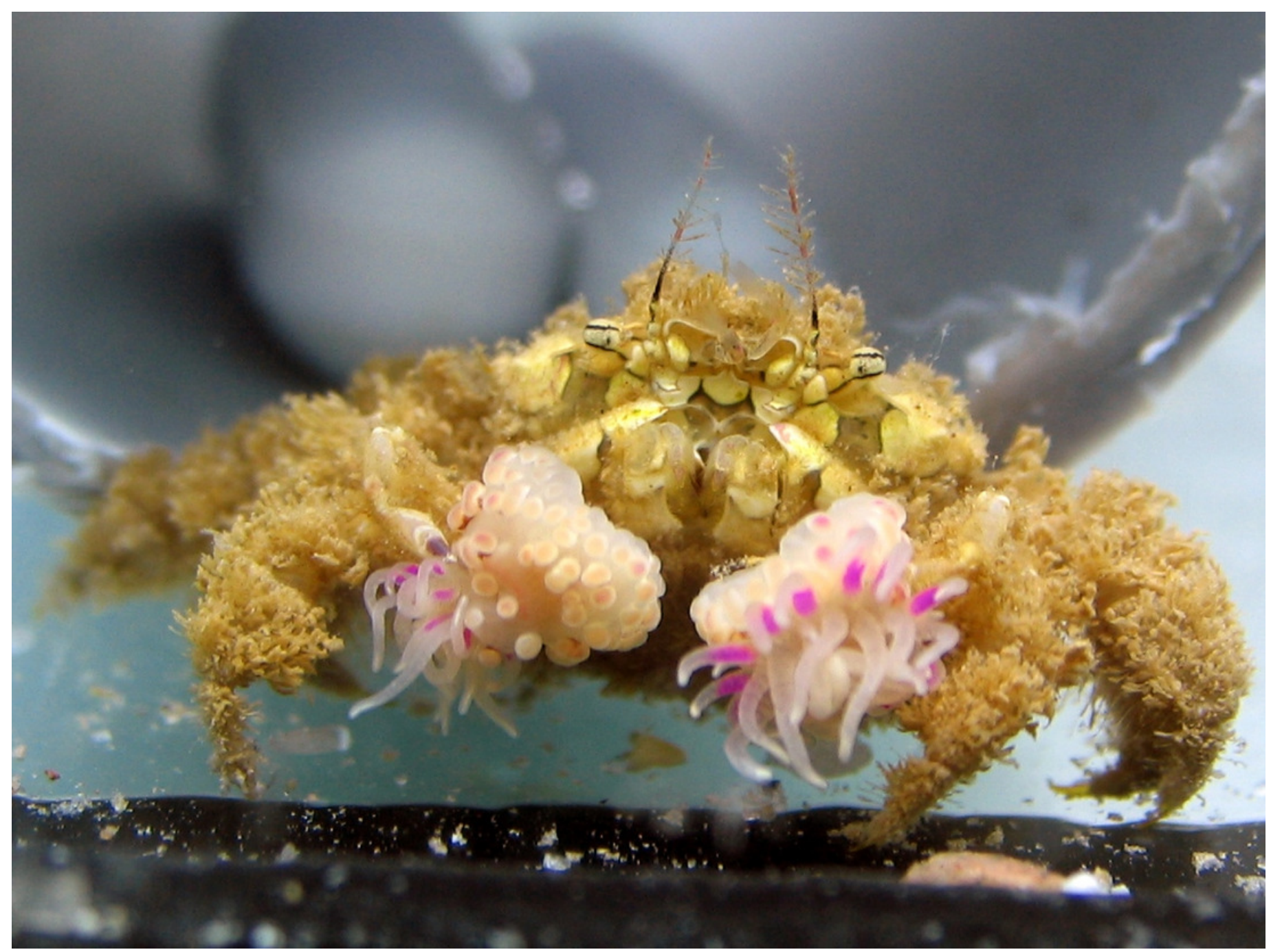


Figure 2

Correlation between left and right held anemones as observed in nature.

Lybia leptochelis hold significantly similar sized Alicia sp. anemones in each claw. ( $r=0.90$, $\left.t_{52}=14.883, P>0.0001\right) . P D D=$ pedal disc diameter measurements are in $\mathrm{mm}$.

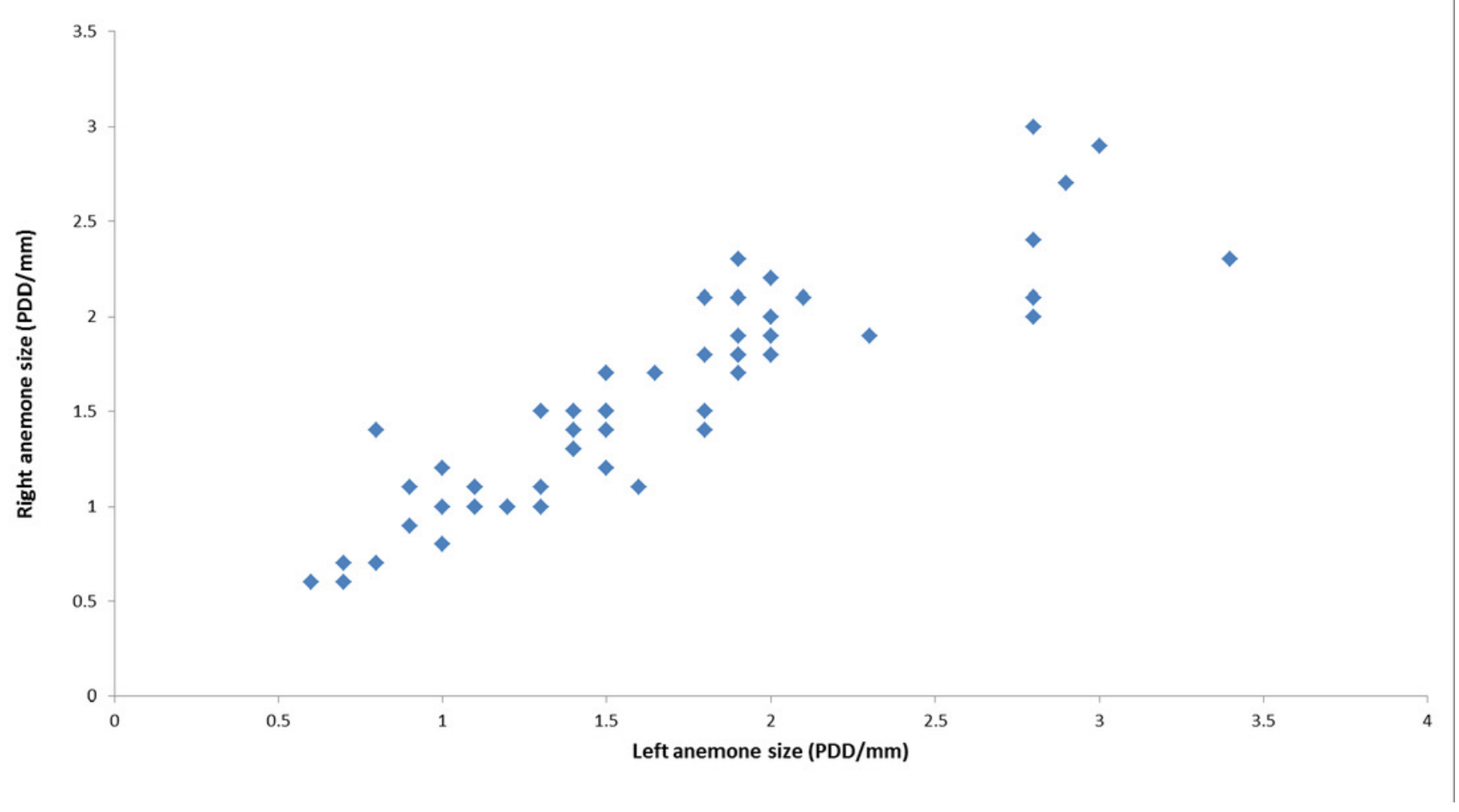


Figure 3

Correlation between held anemones (average of left and right anemones) and crab size as observed in nature.

$\left(r=0.72, t_{52}=7.4546, P<0.0001\right)$. PDD $=$ pedal disc diameter. $C W=$ Carapace width measurements are in $\mathrm{mm}$.

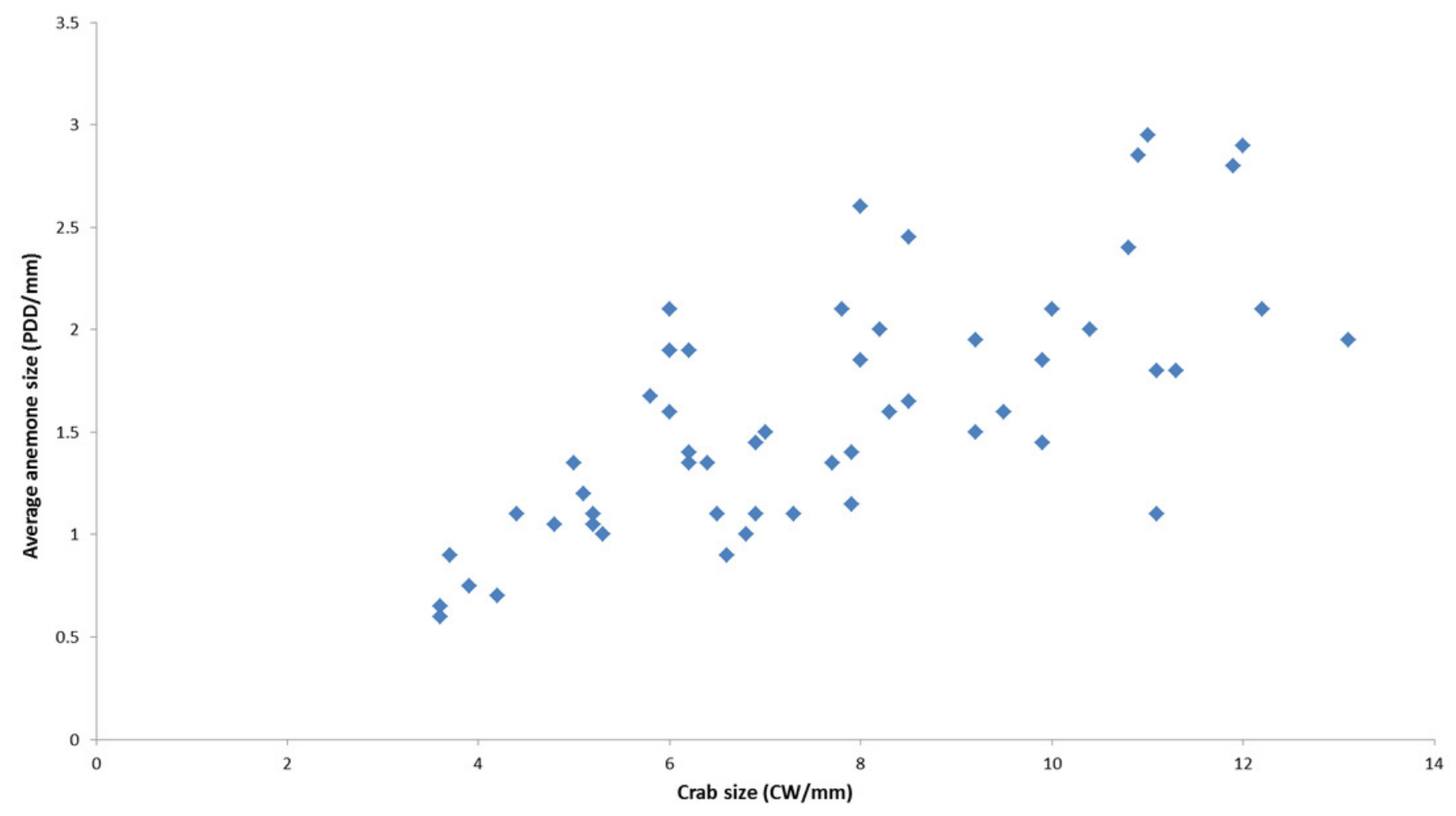




\section{Figure 4}

Sequence of anemone splitting behavior.

This particular trial took approximately 1.2 hours until splitting was completed. Time presented in hh:mm format. (A) - Lybia leptochelis holding an Alicia sp. in one claw the second is vacant. (B) - Typical anemone splitting conformation with pedal disc up and oral disc/tentacles down. (C) - Stretching of the anemone between both claws and use of front walking legs to tear it down the middle. (D) - Tearing of anemone into two. (E) - Final strands of anemone tissue are cut with front walking legs. (F) - L. leptochelis holding two identical clones of the original Alicia sp. anemone. 


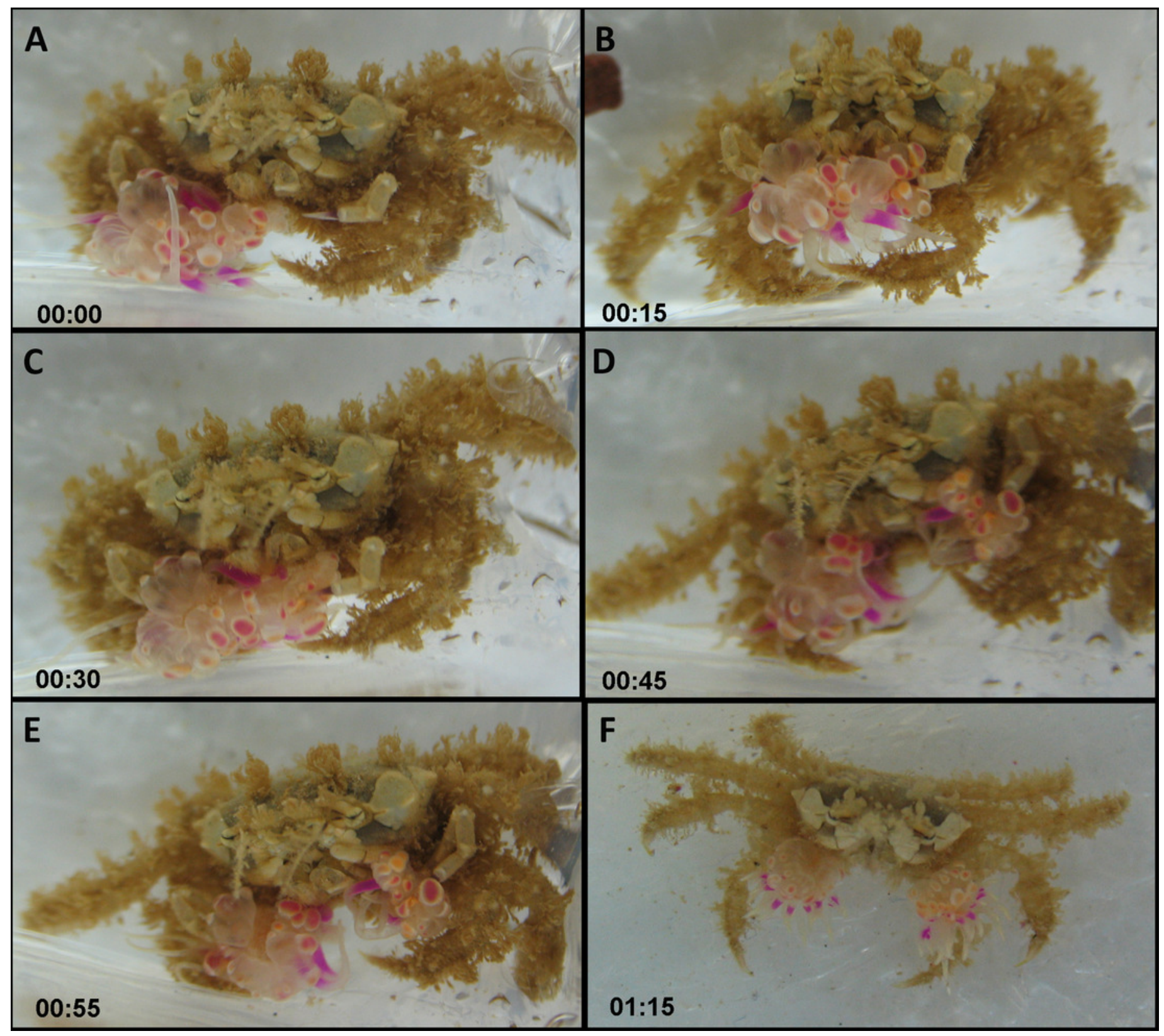


Figure 5

Sequence of anemone theft behaviour line drawing from video.

Time presented in mm:ss. Please refer to the results section for elaboration on theft sequence. 


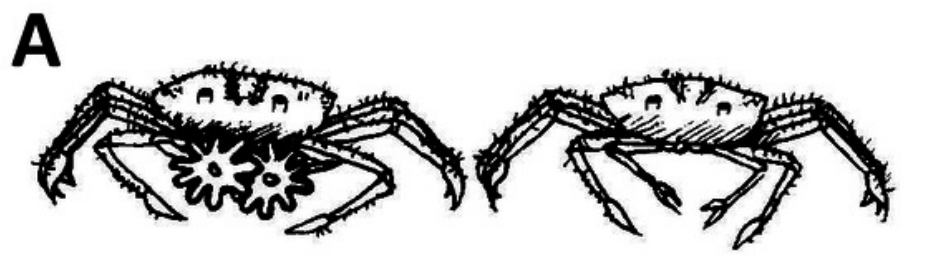

B

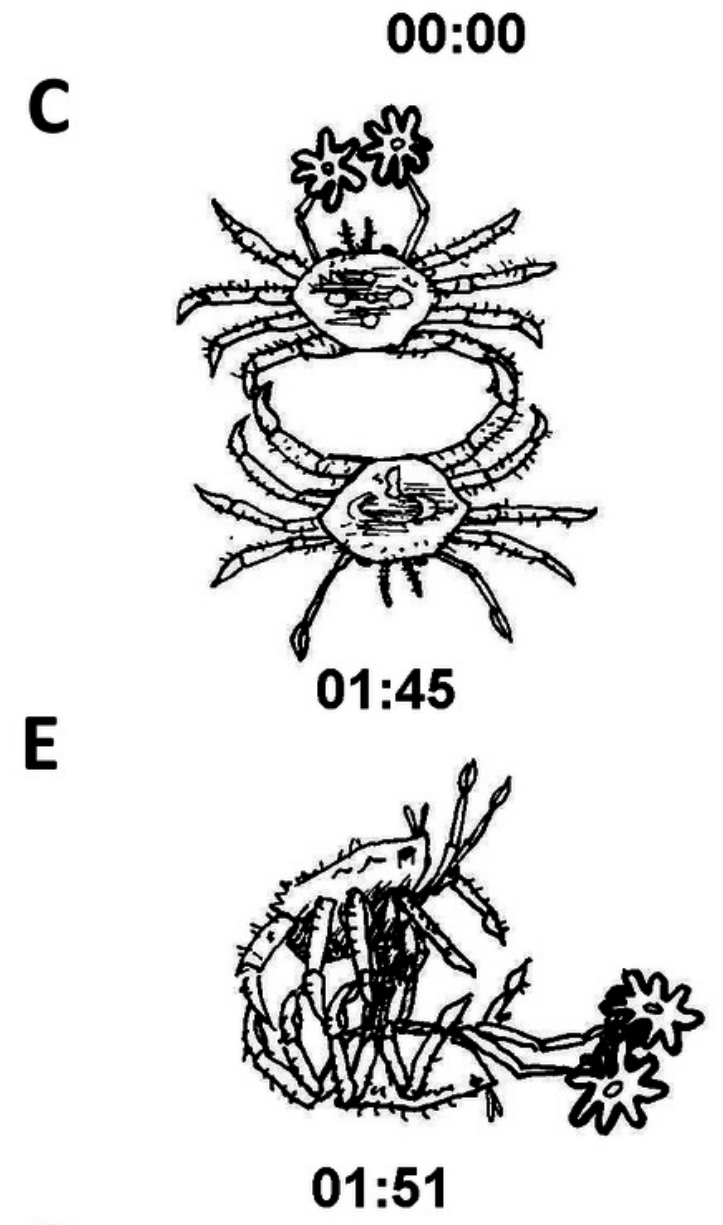

$\mathbf{G}$

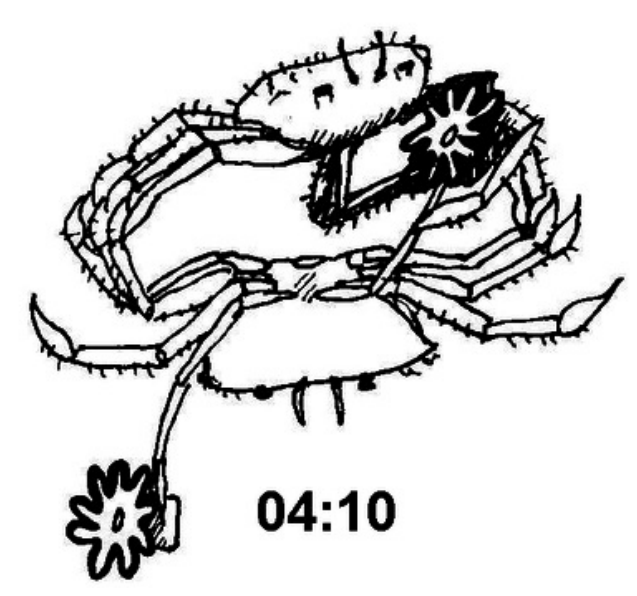

H

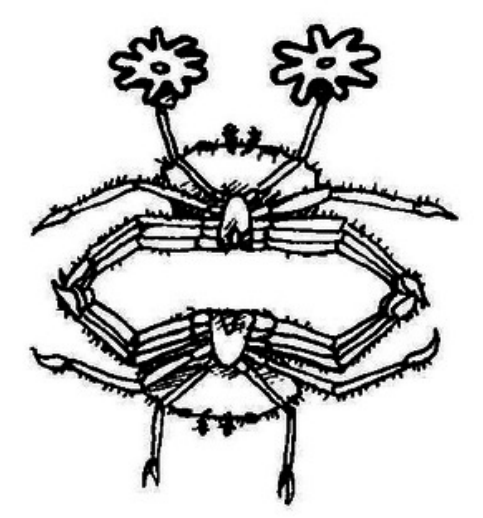

$\mathbf{F}$
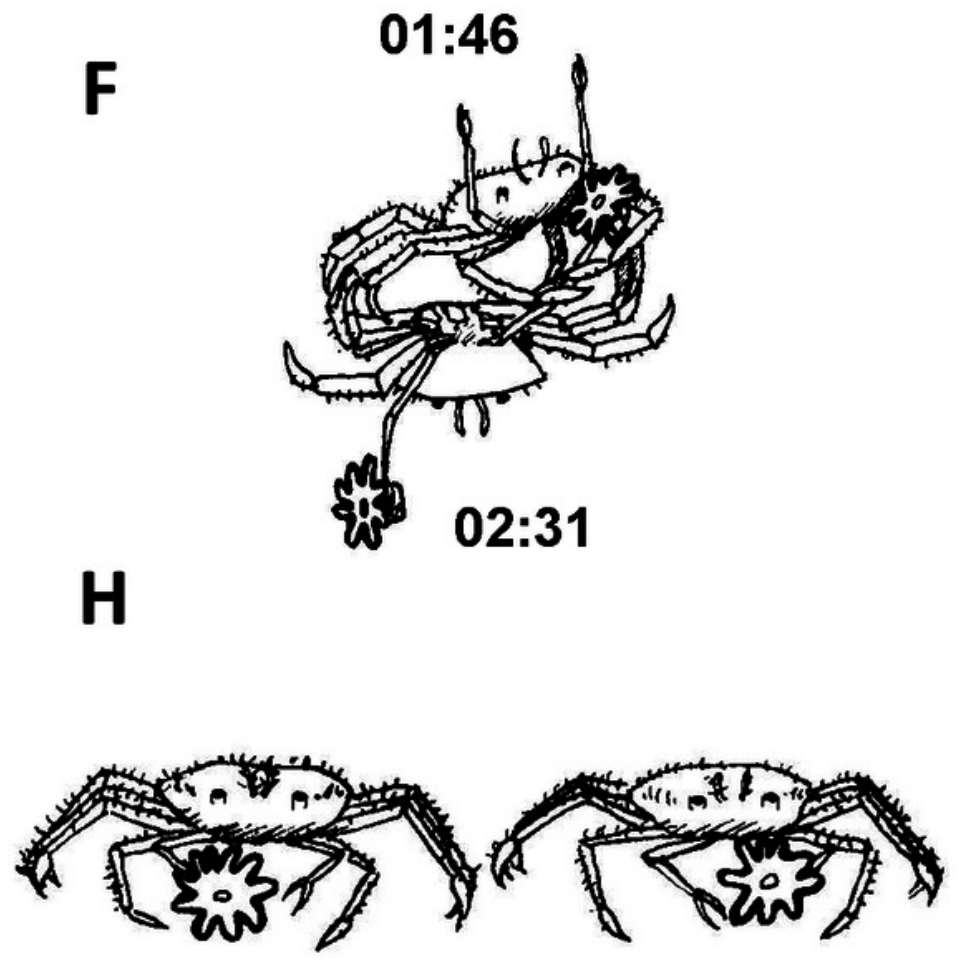

07:00 


\section{Figure 6}

Genetic relatedness of Alicia sp. anemone pairs taken from Lybia leptochelis.

The Maximum Parsimony dendogram is the combined results of 3 different primer combinations. Collection location: Ty - Tur Yam; Rr - Red rock. Each pair of letters represents a pair of anemones originating from a single $L$. leptochcelis. 


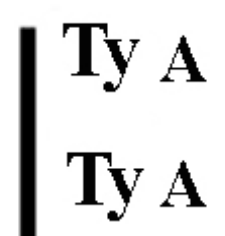

Ty B

Ty C

Ty C

Ty $D$

Ty $D$

Ty $E$

Ty E

Rr F

Rr F

$\operatorname{Rr} \mathbf{G}$

$\operatorname{Rr} \mathbf{G}$

1 change

94| $\left.\right|_{\text {Rr H H }} ^{\operatorname{Rr~H}}$ 


\section{Table 1 (on next page)}

Anemone splitting by Lybia leptochelis following removal of one of its anemones. 


\begin{tabular}{|c|c|c|c|c|c|c|c|c|}
\hline $\begin{array}{c}\text { Crab } \\
\text { Number }\end{array}$ & $\begin{array}{l}\text { Crab } \\
\text { Gender }\end{array}$ & $\begin{array}{c}\text { Crab Carapace } \\
\text { Width (mm) }\end{array}$ & $\begin{array}{c}\text { Remaining } \\
\text { Anemone Size; held } \\
\text { by left ( L ) or right } \\
\text { ( R ) claw }\end{array}$ & $\begin{array}{l}\text { Anemone } \\
\text { Splitting }\end{array}$ & $\begin{array}{l}\text { Time to split } \\
\text { (hours) }\end{array}$ & $\begin{array}{l}\text { Size of Anemone held in right } \\
\text { claw 10-14 days following } \\
\text { splitting }\end{array}$ & $\begin{array}{c}\text { Size of Anemone held in left } \\
\text { claw 10-14 days following } \\
\text { splitting }\end{array}$ & $\begin{array}{l}\text { Asymmetry } \\
\text { index }\end{array}$ \\
\hline 1 & $\mathrm{~F}$ & ---- & $0.9(\mathrm{R})$ & ---- & ---- & 1.1 & ---- & --- \\
\hline \multirow[t]{2}{*}{2} & M & 4.2 & & + & 4 & 0.8 & 0.8 & 0 \\
\hline & & & $1.0(\mathrm{~L})$ & & & & & \\
\hline 3 & M & 4.1 & $1.1(\mathrm{~L})$ & + & 4 & 0.8 & 0.8 & 0 \\
\hline 4 & $\mathrm{~F}$ & 4.7 & $1.1(\mathrm{R})$ & + & 48 & 0.8 & 0.8 & 0 \\
\hline 5 & M & 4.5 & $1.1(\mathrm{~L})$ & + & 36 & 1.0 & 0.9 & $10 \%$ \\
\hline 6 & M & 4.4 & $1.1(\mathrm{~L})$ & ---- & ---- & ----- & 1.1 & --- \\
\hline 7 & M & 4.7 & $1.2(\mathrm{R})$ & + & 4 & 0.8 & 0.8 & 0 \\
\hline 8 & M & 4.7 & $1.2(\mathrm{R})$ & + & 4 & 0.8 & 0.8 & 0 \\
\hline 9 & $\mathrm{M}$ & 4.1 & $1.3(\mathrm{R})$ & + & 36 & 1.1 & 0.9 & $18 \%$ \\
\hline 10 & $\mathrm{~F}$ & 6.3 & $1.3(\mathrm{~L})$ & + & 36 & --- & --- & -- \\
\hline 11 & $\mathrm{~F}$ & ---- & $1.4(\mathrm{~L})$ & ---- & ---- & ---- & 0.9 & --- \\
\hline 12 & M & ---- & $1.4(\mathrm{~L})$ & + & 12 & ---- & --- & --- \\
\hline 13 & M & 8.0 & $1.5(\mathrm{~L})$ & + & 12 & 1.3 & 1.2 & $7.7 \%$ \\
\hline 14 & M & ---- & $1.6(\mathrm{R})$ & ---- & --- & 1.8 & --- & --- \\
\hline 15 & $\mathrm{~F}$ & ---- & $1.6(\mathrm{R})$ & + & 24 & 1.4 & 1.2 & $14.3 \%$ \\
\hline 16 & M & ---- & $1.6(\mathrm{R})$ & + & 144 & 1.1 & 0.9 & $18 \%$ \\
\hline 17 & $\mathrm{~F}$ & ---- & $1.7(\mathrm{R})$ & + & 24 & 1.5 & 1.1 & $26.6 \%$ \\
\hline 18 & $\mathrm{~F}$ & 10.1 & $1.8(\mathrm{R})$ & + & 72 & 1.1 & 1.2 & $8.3 \%$ \\
\hline 19 & $\mathrm{M}$ & 8.6 & $1.8(\mathrm{R})$ & ---- & --- & 2.0 & --- & --- \\
\hline 20 & $\mathrm{M}$ & 8.0 & $2.0(\mathrm{~L})$ & + & 1 & 1.4 & 1.3 & $7.1 \%$ \\
\hline 21 & M & --- & $2.1(\mathrm{R})$ & + & 24 & ---- & ----- & --- \\
\hline 22 & $\mathrm{~F}$ & ---- & $2.5(\mathrm{R})$ & + & 12 & ---- & ---- & --- \\
\hline
\end{tabular}




\section{Table 2 (on next page)}

Multiple linear regression model of (A) Time to split and (B) Asymmetry index. 
2

\begin{tabular}{|c|c|c|c|}
\hline Factor & Coefficient & $\mathrm{SE}$ & $\mathrm{t}$ \\
\hline \multicolumn{4}{|c|}{ (A) Time to split } \\
\hline Constant & 5.3369 & 2.3896 & 2.233 \\
\hline Crab gender & -2.1798 & 1.1833 & -1.842 \\
\hline Anemone size & -1.0365 & 1.2963 & -0.800 \\
\hline Handedness & 0.2399 & 0.9300 & 0.258 \\
\hline \multicolumn{4}{|c|}{$F_{3,6}=1.852, R_{A d j}^{2}=0.2211, P=0.2385$} \\
\hline \multicolumn{4}{|c|}{ (B) Asymmetry index } \\
\hline Constant & -0.285792 & 0.067879 & $-4.210 * *$ \\
\hline Crab gender & 0.197162 & 0.042242 & $4.667 * *$ \\
\hline Time to split & 0.003594 & 0.000705 & $5.098 * *$ \\
\hline Anemone size & 0.072579 & 0.030737 & $2.361^{\wedge}$ \\
\hline Handedness & 0.006401 & 0.022159 & 0.289 \\
\hline$F_{4,5}=8.351, R_{A d j}^{2}=$ & .01941 & & \\
\hline
\end{tabular}




\section{Table 3(on next page)}

Theft of anemones during encounters between Lybia leptochelis with and without sea anemones. 


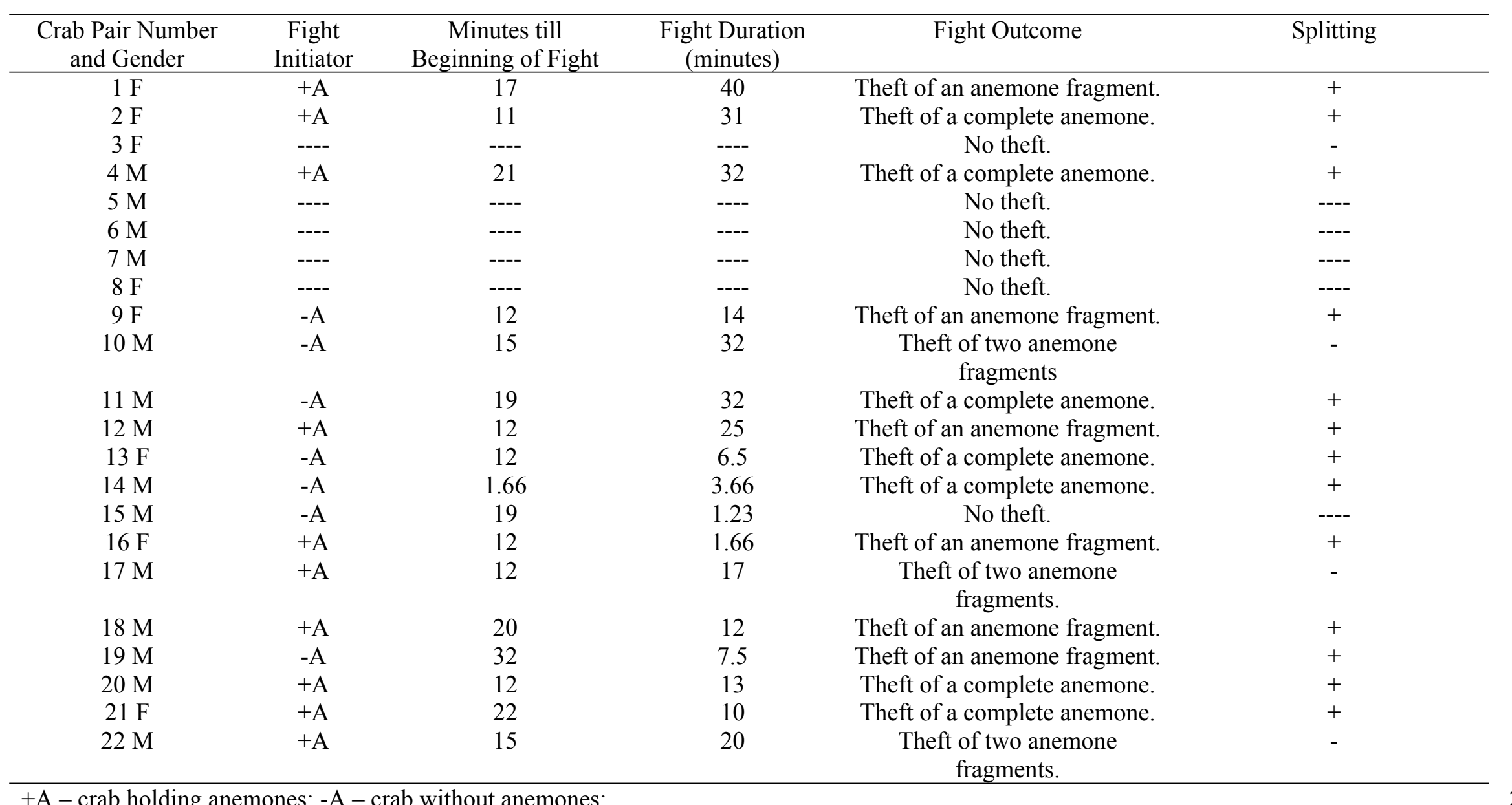

$+\mathrm{A}-$ crab holding anemones; $-\mathrm{A}-$ crab without anemones; 


\section{Table 4(on next page)}

Two-way ANOVA investigating the effect of crab gender and fight initiator on time until start of fight. 
1

\begin{tabular}{ccccl}
\hline Source of variation & $d f$ & Sum & $F$ & $P$ \\
\hline Constant & 1 & 288.0 & 5.89 & 0.031 \\
Crab gender & 1 & 40.61 & 0.83 & 0.379 \\
Initiator & 1 & 16.33 & 0.33 & 0.573 \\
Crab gender X initiator & 1 & 27.08 & 0.55 & 0.470 \\
Error & 13 & 636.1 & & \\
\hline
\end{tabular}

2 Initiator-Crab with or without anemones

3 


\section{Table 5 (on next page)}

Multiple linear regression model of fight duration. 
1

\begin{tabular}{cccc}
\hline Factor & Coefficient & SE & $\mathrm{t}$ \\
\hline Constant & 16.4062 & 6.4844 & 0.0264 \\
Crab gender & 0.5742 & 7.3154 & 0.9387 \\
Complete anemone & 1.5742 & 7.3154 & 0.8332 \\
Two fragments & 6.0196 & 9.9692 & 0.5572 \\
$F_{3,12}=0.158, R_{A d j}^{2}=-0.2025, P=0.923$ & & \\
\hline
\end{tabular}

2

3 
Table 6(on next page)

Pairwise unbiased (Nei, 1978) genetic identities (above diagonal) and genetic distances (below diagonal) between Alicia sp. anemone removed from single crab. Collection location and pair of crab are indicated: Ty - Tur Yam; Rr - Red rock; each capit 


\begin{tabular}{ccccccccc}
1 & & & & & & & \\
\hline Pop ID & RrH & TyB & TyC & TyD & TyE & RrF & RrG & TyA \\
\hline RrH & & 0.7931 & 0.7931 & 0.7931 & 0.7931 & 0.7931 & 0.7931 & 0.8759 \\
TyB & 0.2318 & & 1.0000 & 1.0000 & 1.0000 & 1.0000 & 1.0000 & 0.8759 \\
TyC & 0.2318 & 0.0000 & & 1.0000 & 1.0000 & 1.0000 & 1.0000 & 0.8759 \\
TyD & 0.2318 & 0.0000 & 0.0000 & & 1.0000 & 1.0000 & 1.0000 & 0.8759 \\
TyE & 0.2318 & 0.0000 & 0.0000 & 0.0000 & & 1.0000 & 1.0000 & 0.8759 \\
RrF & 0.2318 & 0.0000 & 0.0000 & 0.0000 & 0.0000 & & 1.0000 & 0.8759 \\
RrG & 0.2318 & 0.0000 & 0.0000 & 0.0000 & 0.0000 & 0.0000 & & 0.8759 \\
TyA & 0.1325 & 0.1325 & 0.1325 & 0.1325 & 0.1325 & 0.1325 & 0.1325 & \\
\hline
\end{tabular}

2 Ty-Tur Yam; Rr - Red rock. 